This item was submitted to Loughborough's Research Repository by the author.

Items in Figshare are protected by copyright, with all rights reserved, unless otherwise indicated.

\title{
The Little Stranger -A study of the heteropatriarchal male and the dynamics of masculine domination
}

PLEASE CITE THE PUBLISHED VERSION

https://www.bloomsbury.com/uk/sarah-waters-gender-and-sexual-politics-9781474271516/

\section{PUBLISHER}

Bloomsbury

VERSION

AM (Accepted Manuscript)

\section{PUBLISHER STATEMENT}

This work is made available according to the conditions of the Creative Commons Attribution-NonCommercialNoDerivatives 4.0 International (CC BY-NC-ND 4.0) licence. Full details of this licence are available at: https://creativecommons.org/licenses/by-nc-nd/4.0/

\section{LICENCE}

CC BY-NC-ND 4.0

\section{REPOSITORY RECORD}

O'Callaghan, Claire. 2019. "The Little Stranger -A Study of the Heteropatriarchal Male and the Dynamics of Masculine Domination”. figshare. https://hdl.handle.net/2134/34813. 


\section{5}

\section{The Little Stranger -A study of the heteropatriarchal male and the dynamics of masculine domination}

Told through the eyes of General Practitioner Dr Faraday, The Little Stranger (2009)— Waters's third novel to be nominated for the prestigious Man Booker prize—charts the demise of the Ayres family of Hundreds Hall. Faraday is called to Hundreds (as it is affectionately known) in 1947 to treat an "ill” maidservant, Betty, and finds that the Hall, once a grandiose stately country house he fondly remembers from his childhood, is now dilapidated — both it and its inhabitants, the widowed Mrs Ayres and her adult children, Roderick and Caroline, exist in a state of decay. He befriends the family, becoming a regular visitor to the Hall, but he soon comes to play an important role in the tragedies that befall the Ayres, which, initially, are attributed to a poltergeist- the little stranger of the novel's title. First Roderick undergoes a mental breakdown of sorts and is hospitalized in nearby Leamington Spa, before then Mrs Ayres suffers a similar breakdown and commits suicide. That leaves Caroline, the sole heir to the Hall, who plans to marry Faraday, but quickly abandons this idea in favour of relocation to Canada. Before she does so, however, she, too, succumbs to tragedy; she is found dead at the bottom of the Hall's lavish staircase mysteriously having been overheard calling out 'you' before falling to her death (Waters 2009a: 482). The novel ends with the house empty and Faraday in a self-appointed role as caretaker, unable discern if Hundreds was ever truly haunted by a ghost that caused the tragedies. 
What's particularly significant about The Little Stranger is that not only is Faraday Waters's first male narrator, but there are no overt homosexuals in the text. ${ }^{1}$ Her move away from an explicit lesbian subject matter is a significant departure from her earlier works and it is tempting to read this choice as a questioning of the epistemology and ontology of the category "lesbian" that considers what being a lesbian means in both theory and textual practice. I do not pursue this particular avenue here, but I do wish to focus on the significance of Waters's authorial decision to narrate this novel through the first-person perspective of a heterosexual male subject.

This chapter proposes that The Little Stranger constitutes a study in masculinity, specifically heteropatriarchal masculinity, the mechanisms by which it is "formed" (for want of a better term) and its modes of operation. As Marianne Hester puts it, 'to analyse and understand male supremacy, we need to study men: their behaviours, sexuality, institutions, and so on, because that is where the power lies’ (1992: 3). Reflecting Hester’s important point, I argue that the novel offers an account of the insidious nature of heteropatriarchal domination and an expose of gendered violence towards, and against, "non-normative” gendered and sexual subjects. The “non-normative” individuals here are represented by Roderick and Caroline who, I suggest, like Vivian in The Night Watch, are queer heterosexual figures as they too defy, in various ways, the normative conventions of gender and sexuality, troubling (to use a Butlerian term) Faraday’s heteropatriarchal ideals. In privileging a heteropatriarchal perspective, Waters offers a subtle analysis of the politics of male heterosexuality, revealing the phallonarcissistic vision and androcentric cosmology of heteropatriarchal men. Through the novel she sets out the process by which men sometimes “morph” into domineering heteropatriarchal figures, and represents the gendered and sexual means by which such dominant male figure wield power over "non-normative” subjects. Via the events which befall the Ayres family, Waters subtly combines feminist and queer 
critiques of heteropatriarchy, its pernicious means of operation, and the distorted means by which "non-normative" gendered and sexual subjects (male and female alike) are often suffocated beneath the weight of heteropatriarchal oppression.

Unlike The Night Watch, The Little Stranger is not a novel about the sexual margins to which "non-normative” gendered and sexual subjects are relegated but rather, focused on the sexual centre that gives those margins their shape. As chapter four suggested, without an understanding of the dominant gendered and sexual culture, it is impossible to understand the depth of resistance engaged in by straight women, lesbians, gay men, and others who have long been unwilling or unable to conform to prevailing definitions of gender and sexual normality and the social regulations imposed upon them to (re)produce that normality in the first place. As such, Waters’s fifth novel provides a literary response to Eve Kosofsky Sedgwick's contention that:

an understanding of virtually any aspect of modern Western culture must be, not merely incomplete, but damaged in its central substance to the degree that it does not incorporate a critical analysis of modern homo/heterosexual definition (1990: 1).

Sedgwick's comment is important in reinforcing how heterosexuality as an institution depends on homosexuality as a means to define and sustain 'the fictions of its identity' (Carroll 2012: 6).

Importantly, Stevi Jackson has argued that second-wave feminism ‘failed to fully problematise heterosexuality' and illuminate it 'as an organising institution', identity, sexual practice and experience that is 'organised around a hetero/homo binary, a symmetrical and oppositional coupling of a marginal category (homosexuality) and a privileged class’ (1999: 2; Yep 2003: 12). As Diane Richardson notes, 'within social and political theory little attention has traditionally been given to theorizing heterosexuality’ more broadly, despite the fact that it is 'deeply embedded in accounts of social and political participation' (1996: 1). 
For her, this omission stems from the fact that heterosexuality is so culturally institutionalized that it "tends to be taken for granted, as something that is "natural” and "normal”" (Ibid: 2). Heterosexuality is complex because it is both an institution, an identity, a sexual practice, and an experience, but as Richardson reminds us, it is institutionalized as a 'particular form of practice and relationships, of family structure, and identity’ precisely because it is constructed as 'coherent, natural, fixed and stable [;] as universal and monolithic' (Ibid). Heterosexuality as a category relies on gender and an acceptance of division between the sexes, and a presumption of its universality and "normalcy” lie at its centre.

Despite Jackson’s perspective, feminisms and queer theories have provided invaluably critiques of heterosexuality, illuminating the ways in which the institution of heterosexuality manifests, fleshing out its co-dependent relationship to queerness. Indeed, as Rachel Carroll notes, lesbian-feminist theories have been 'instrumental in establishing heterosexuality as an object of feminist critique and in setting the terms by which it is approached' (2012: 2). ${ }^{2}$ In her ground-breaking essay, 'Compulsory Heterosexuality and Lesbian Existence' (1980) discussed in chapter two, Adrienne Rich draws attention the naturalization of heterosexuality in modern culture and the ways in which it is presumptively and coercively mapped as a destiny for women. Rich remains unclear why 'such violent structures should be found necessary to enforce women's total emotional, erotic loyalty and subservience to men', but her point elucidates how heterosexuality functions both as a sexual relation and practice and dynamic of power between the sexes (1986: 35). In other words, it is the 'compulsory' nature of heterosexuality that ensures women's subservience to men and demarcates the figure of the lesbian as "other” (Ibid: 23). Extending this, and return to Sedgwick’s observation, Jackson perceives that any understanding of heterosexuality is incomplete without a supplementary consideration of its role as endemic of patriarchy more broadly. For her, hetero-patriarchy ‘or hetero-oppression’ remains critical to gain a deep 
socio-cultural understanding of the ways in which heterosexuality is constituted in and through men (1991: 63).

Queer theoretical work has also been instrumental in outlining how the oppressive components of heterosexuality informs binary modes of gender, sex and sexuality are understood and how it 'encodes and structures everyday life' (Richardson 1996: 1). In Judith Butler's pioneering writings, she asserts that it is the very fact that all persons are required to identify according to heterosexual gender and sexual categories that heterosexuality achieves and maintains its power. As chapter one discussed in depth, in Gender Trouble (1990) Butler questions why a person's sex is assumed to designate both their gender and sexual orientation, and she is concerned to understand the seeming incoherence that ensues from a subject's apparent "failure” to follow such a determining logic. In this way, while 'queer theory has been principally concerned with the hierarchical nature of the heterosexual/homosexual binary' it is has also shown that this 'binary is understood as not so much expressive but constitutive of heterosexual power’ (Carroll 2012: 6). Indeed, more recently, queer theory has been used as a lens through which to understand heteronormativity as a 'privileged' and 'overarching system of male dominance through the institution of compulsive heterosexuality that is dependent on heterosexuality as equivalent to normality’ (Berlant and Warner 1998: 548; Yep 2003: 31).

Building on this analysis is the anthropologically informed analysis of masculine domination by Pierre Bourdieu, which illuminates the particular mechanisms through which heteropatriarchy manifests in society and culture. Reflecting the insights from Rich and Richardson cited above, Bourdieu argues that masculine domination is so ingrained into the social consciousness that “we” hardly perceive of 'all of its dimensions' (2001: n. p.). Because of the unseen and taken-for-granted mechanisms by which masculine domination functions, Bourdieu makes the case for heteropatriarchy to be understood as an exemplary 
form of symbolic violence: 'gentle, imperceptible and invisible even to its victims, exerted for the most part through the purely symbolic channels of communication and cognition, recognition, or even feeling (2001: 1-2).

Usefully, Bourdieu turns to Virginia Woolf's to elucidate the gender and sexual politics at stake here, reminding us of what Woolf names 'the hypnotic power of domination' that

Inflate[s] [...] a monstrous male, loud of voice, hard of fist, childishly intent upon scoring the floor of the earth with chalk marks [.] [H]e goes through mystic rites and enjoys the dubious pleasures of power and domination while we, "his” women, are locked in the private house. (2007: 2)

As Bourdieu points out, Woolf's language—which, I will show, resonate with aspects of The Little Stranger — call for a demystification of the ways in which heteropatriarchy and masculine domination functions. This chapter suggest that it is precisely such a study that Waters's provides in The Little Stranger. But where Woolf perceives women as the sole subjects of masculine oppression, in her novel, Waters emphasizes the co-dependent relationship between heterosexuality and queerness, reminding us that it is queer figures more broadly who are equally subject to heteropatriarchal subjugation, exposing the violence with which heterosexuality is often produced against queerness, thus endorsing Calvin Thomas’s call for further understandings of heterosexual engagements with queer identities.

\section{The Male Subject}

As discussed in relation to chapter four, the post-war setting supplies a fertile context for examining the politics of heterosexuality and heteropatriarchy. The Little Stranger continues in the historical moment where The Night Watch began, 1947, a period in which the Labour government that came into power at the end of the war established the Welfare State, the 
National Health Service and through the 1944 Education Act, the ability for all citizens to benefit from education at all levels. But where Waters focuses on the transition from war to peace and its effects on gender roles and sexual freedoms in The Night Watch, in The Little Stranger, she scrutinizes the heterosexual politics at play in the production (or reconstitution) of such socio-cultural changes. Such a point is important because not only is the post-war moment is remembered as an era in which family values and traditional morals re-affirmed heteropatriarchal structures, but as Mary Louise Adams argues:

In contemporary sexual politics, the period is viewed as a standard against which gender and sexual conservatives measure changes in the organization of sexuality. The mores of that period sit as a benchmark, a symbol of how far gender and sexuality has travelled since morality was 'as it should be', with clear gender roles in every household, and heterosexual conjugal monogamy as the primary form of sexual partnership. That this portrait is an idealized one does not decrease its effectiveness in contributing to present-day anxieties about changing sexual behaviours and identities (1997: 3).

As a historical period setting, the 1940s lend themselves to a study of heterosexuality and its dependency on queerness for definition. Importantly, as Adams also notes, 'a study of the late 1940s [...] makes apparent the ideological underpinnings of the nostalgia that currently runs counter to the gains made by feminists, gay men, and lesbians over the past two decades' (Ibid: 4). In existing criticism of the novel, numerous scholars have identified the presence of nostalgia in the text. ${ }^{3}$ However, in her reading of the novel, Ann Heilmann has valuably read The Little Stranger's intertextual framework as providing a specific return to nineteenthcentury literature and culture, finding ‘echoes of the Victorian’ in Waters’s haunted house, her portrayal of Roderick's ill health and subsequent decline, and the representation of the paranormal. ${ }^{4}$ Building on Heilmann’s rich insights, I also suggest that Faraday’s nostalgically 
yearns for the Victorian past, and specifically a Victorian image of the past that Hundreds represents. But I also suggest his nostalgia is built on an idealization of nineteenth-century gender and sexual politics in which heteropatriarchal domination prevailed and was manifest most obviously in the role of "master of the house".

Aptly, Waters begins the novel with Faraday's childhood memory of the Empire Day commemorations from 1919 that were held at Hundreds Hall. As Heilmann indicates, 'Empire Day served to induct British youngsters into an unquestioning allegiance to traditional models of author and to the principles of patriotism and imperialism', but on this occasion at Hundreds Hall, the day is also 'intended to celebrate the post-World War 1 restoration of Victorian values and social hegemonies' (2012: 39). Faraday's memories here are important because he in addition to exposing his passionate desire for the majestic nature of the house and his admiration for the Ayres, Waters uses the opening to also illuminate just what kind of a male subject her narrator truly is.

Indeed, through Faraday’s memory he foregrounds the complex relationship he has to gender, desire and heteropatriarchal values. He remembers not only 'admiring' the house, but wanting to 'possess it' (Waters 2009a: 3). Waters's use of the term 'possess' here is twofold, connoting possession in a Gothic and/or supernatural context and evoking the primary meaning of the word in terms of ownership. Troublingly, Faraday goes onto to recount how, fuelled by his desire for the house, he used a pen knife to prise a piece of Hundred's decorative wall plaster free from its setting. Worryingly, he admits that it was 'simply' that his 'admiration' for the house 'entitled' him to it and goes on-as an adult—-to rationalize his behaviour using gendered and specifically heteropatriarchal imagery: 'I was like a man [...] wanting a lock of hair from the head of a girl he had suddenly [...] become enamoured of', he reflects, rationalizing his boyhood actions in the guise of adult male behaviour (Ibid: 3). 
In offering this troubling account of Faraday's boyhood “antics”, Waters alerts us to his dubious character and unreliability as a narrator. Faraday’s memory positions him as a somewhat unsavory male figure and the context establishes the novel's complex heteropatriarchal moral framework. As Faraday himself indicates, he received no reprisal from his mother, who discovered his vandalism when she sees chalk marks trailing from his pocket upon the floor. Put another way, Faraday failed to learn a valuable moral lesson about possession at a young and impressionable age, leaving him with a sense of entitlement that he (re)configures in gendered terms and carries on in adulthood. In addition, Waters's carefully chosen reference to the chalk marks on the floor recall Woolf's own conception of the 'monstrous male' child who grows up into a domineering patriarch because he is 'intent upon scoring the floor of the earth with chalk marks' (Bourdieu 2007: 2). As such, through this intertextual allusion, Waters indicates how the young Faraday aspired to be a patriarchal male and warns us of the violence within which Faraday’s (future) behaviour at Hundreds Hall will be constituted.

Significantly, Waters has stated that 'the main technical challenge [in the novel] in what was otherwise pretty straightforward writing [was] how to maintain Dr Faraday’s bland narrative surface, while finding ways to suggest that there was a whole layer of sometimes turbulent activity going on just beneath it' (2010: n. p.). Her comment reinforces the complexity with which he functions as a narrator and character. Importantly, as an adult, Faraday’s seemingly respectable and bland voice establishes a "normative” point of view and his perspective is given added authority by his position as the town's GP. Scholars from Michel Foucault to Butler have argued that gender and sexuality is discursively constituted through socio-cultural and political institutions, of which medicine is a leading proponent and, as I will show, Faraday’s clinical gaze plays a central role in the gender and sexual politics that unfold at Hundreds Hall. But I wish to pause momentarily to interrogate the 
construction of masculinity that Waters presents because coupling the power of his clinical position, Faraday also embodies Raewyn Connell’s conception of hegemonic masculinity, a mode of masculinity that Connell persuasively argues is accepted as the dominant male prototype.

Hegemonic masculinity is an idealized form of masculine gender associated with popular and cultural stereotypes surrounding the category "man” that hinge on 'heterosexuality, economic autonomy, being able to provide for [others], being rational, being successful, keeping one’s emotions in check, and above all not doing anything considered feminine’ (Alsop, Fitzsimmons and Lemmon 2002: 141). Within a heteropatriarchal culture, failure to adhere to such strict gendered typography calls into question the legitimacy and authority of the male subject's masculinity. In the novel, Faraday is, in many respects, a representative of hegemonic masculinity: he is a white, heteronormative, male subject and, in line with Rachel Alsop, Annette Fitzsimmons and Kathleen Lemmon’s definition above, his role as a medical practitioner requires him to be rational, to provide for others, and to restrain his emotions at all times, traits he goes onto displays in moments when his clinical training is called upon, such as when Gillian Baker-Hyde suffers a dog-bite or he discovers that Mrs Ayres appears to be self-harming. However, Waters complicates Faraday’s masculine identity by refusing him stability as a prototype of hegemonic masculinity, problematizing his character through class, intellect, and his gendered and sexual status (a notion already implicated in his wanton vandalism of the Hall as a child), thus calling into question his authority as a hegemonic male. ${ }^{5}$

Despite being a local GP with stature and authority, Faraday is, in fact, an embittered working-class man "cum good”; a figure aggrieved by the demanding pressure of being the 'clever boy' in his youth, a characteristic that continues to haunt him as an adult and induce odd 'secret rages', as he puts it (Waters 2009a: 4). The emphasis on the hidden nature of his 
'rages' suggest that outwardly Faraday maintains a civilized and rational image, but inwardly and within private he is somewhat tormented. At times, however, Faraday is vocal about the 'discontent' he feels about being from 'labouring stock', such that Caroline notes that when Faraday speaks of his family history he talks as though he hates himself (Ibid: 246, 37). In addition, whereas the Ayres have been brought up to believe that their family is 'better and braver' than most, Faraday resents their superiority (Ibid: 398). His mother had been a servant at the Hall, but the family barely remember her. The culminate effect of these class and gendered grievances make Faraday a complex figure, a man who aspires for power and authority, but wrestles with class inequality and his working-class origins.

Importantly, Waters also points to the instability of Faraday’s identity through the way in which he insists on comparing himself to other male figures. Faraday measures himself against his friend and medical partner, Dr David Graham, who, as his doubly masculine name suggests, represents masculinity incarnate, the epitome of heteropatriarchy to which Faraday aspires. That Waters denies Faraday a first name, a comparison that evokes Daphne Du Maurier's nameless narrator in Rebecca (1938), implies in the rhetoric of heteronormativity that Faraday is half the man his friend is. Waters plays this dynamic out through Faraday's own comparative commentary. While Faraday reminds us that he is single, Dr Graham is married (although Faraday regularly "gatecrashes” Sunday dinners with David and his wife, Anne). Graham is younger than Faraday but he is, as Faraday puts it, doing 'rather better' because he had entered the medical profession 'as a doctor's son, with money and standing', all of which, Faraday admits upset him (Ibid: 35). Faraday is aggrieved that his parents have suffered debt, damaged health, and premature death for him to achieve any success as a qualified GP. Disappointments in his career also find expression in Faraday’s own perception of his lesser professional status in the town. He is deemed not 'grand-enough' to be accepted as a doctor by the either the working-class or the gentry, a notion 
foregrounded in the scenes in which Faraday treats Gillian's facial wounds and he is patronized by the Baker-Hyde’s family doctor (Waters 2009a: 36). Moreover, while Dr Graham is viewed as ‘a nice clean handsome sort of family chap’, Faraday perceives himself as misplaced within the community (Ibid: 36). In discussion with David, he comments that: They [society] don’t like me. They never have. They've never been able to place me. I don't hunt or play bridge, but I don't play darts or play football either. I'm not grand enough for the gentry—not grand enough for working people, come to that. (Ibid: 36) Faraday feelings of social misplacement are located in class and gendered stereotypes. Hunting and playing bridge — traits of upper-class masculinity —are not something in which he indulges, while darts and football—-the stereotypical interests of the 1940s working-class man-are likewise, not something he engages in. Faraday, then, is experiencing a crisis in his masculine identity, a notion fuelled by bitterness toward the dynamics of class and the limitations of his professional and socio-cultural position. As a result, he is excluded from the modes of masculinity (heteropatriarchy) with which he wishes to identify and be identified by.

There are a number of important contexts within which Faraday's crisis of masculinity needs to be constituted. Firstly, in his book, On Men (2000), the popular critic Anthony Clare asserts that, 'at the beginning of the twenty-first century it is difficult to avoid the conclusion that men are in trouble' because 'their purpose, their value, their justification' is under public debate (2000: 3). Clare argues that 'there [are] no shortage of suggested causes' for this crisis of gender but that:

Top of the list is the growing assertiveness of women. As a consequence of the feminist revolution, so this argument goes, women are no longer prepared to be the property of men. In this feminist revolution, male power is being overthrown. Men, like colonists seeing their empire crumble, don’t like what’s happening (Ibid: 3-4). 
In this decidedly anti-feminist and somewhat misogynistic evaluation of changes in gender and sexual politics, Clare attributes the decline of heteropatriarchy, and causality of a male gender crisis, to women, a point that reveals an inherent heterocentric bias in his writing, and renders visible a patriarchal view of binary gender categories as co-extensive.

Secondly, with regard to the dynamics of heterosexuality, Clare's comment illuminates what Butler, in Gender Trouble (1990), describes as 'the heterosexual matrix', the production of 'coherent identities through coherent gender norms' relating to 'asymmetrical oppositions of “masculine” and “feminine” that make gender intelligible' (1990: 23). For Clare, it is change to the "natural" role of "woman" that has impacted on the normative functioning of "man” and causes a twenty-first century crisis of masculinity. That The Little Stranger was published in 2009 suggests that Waters is drawing parallels between a crisis in masculinity in the twenty-first century and that from the mid-twentieth century past. Indeed, several historians have persuasively demonstrated that wartime changes to women's gender roles in the 1940s also led to a post-war crisis of middle-class masculinity when thousands of soldiers returned to civilian life. ${ }^{6}$ As Stéphanie Genz and Benjamin Brabbon describe, men’s 'heroic displays of masculinity upon the battlefields of Europe and beyond, as they fought to protect British sovereignty, were now redundant within the new social structures and economies of postwar Britain’ (2009: 133). This precarious masculine position finds resonance in the novel as Waters implies that along with the discontent Faraday holds towards his social class and background, his social unease is equally informed by his status as a bachelor and, as I will show later, his military record. In other words, to return to Butler, Faraday’s lack of co-dependency with “woman” places him outside of the heterosexual matrix thus positioning Faraday as a male who does not signify monolithically in hegemonic terms. Indeed, as Mike Donaldson observes, any understanding of hegemonic masculinity is 
predicated on the feminist insight that in general the relationship of men to women is oppression [;] women exist as potential sexual objects for men, while men are negated as sexual objects for men. Women provide heterosexual men with sexual validation, and men compete with each other for this (1993: 645)

Interestingly, while Faraday contends he has little time for women, it is significant that Dr Graham suspects that Faraday’s “problem” is that he has 'too much time to fret in' (Waters 2009a: 36). In other words, Faraday's crisis of masculinity is precisely because he is not sexually validated by a woman. As a result, Graham recommends that Faraday 'ought to get married' because that would 'sort you out' to which Faraday laughs uncomfortably, replying ‘God! I can barely keep myself, let alone a wife and family’ (Ibid: 36). It is interesting given the role of patriarch as breadwinner Faraday presents a financial case here for being a bachelor. Of course, Faraday also reveals that he remains a bachelor because he is still bitter by having been 'thrown over’ by someone else because her family did not deem him ‘suitable match’ (Ibid: 39). In this way, Waters both positions Faraday as non-normative in the matrices of heterosexuality and points to the way in which heteronormativity is dependent on the connection of stable sex and gender signifiers.

Configured in this light, rather than attributing the ghost of Hundreds Hall to an element of the supernatural, I posit Faraday's crisis in masculinity as that which comes to haunt its grounds. ${ }^{7}$ Conceptually, ghosts are, as the novel indicates, a manifestation of an unresolved self, and Caroline is specific that the house is haunted by a poltergeist which is 'part of a person’ (Ibid: 364). According to the Gurney and Myers text that she consults, poltergeists are:

the unconscious parts [of a person], so strong or troubled they can take on a life of their own [....] The book says, with some sorts of people, when they're happy or 
troubled, or they want something badly—sometimes they don't even know it's happening. (Ibid: 364).

As Caroline indicates, the discontent from a poltergeist can come about purely through desire and entitlement. Aptly, in both Gender Trouble (1990) and her essay 'Critically Queer' (1993), Butler theorizes the production of the heterosexual subject in terms of spectres and phantasms. By evoking such imagery, Waters posits Faraday as a spectre of the heteropatriarchal male subject, a stranger (as the novel's title suggests) who brings into the Hall's parameters the ideology of heteropatriarchy, and who is aggrieved by his own inability to be the master of the house. Faraday needs to "exorcise" his unresolved gender crisis in order to satisfy his authority and sense of entitlement to the Hall, something later endorsed Betty's by observation that the ghost wanted the house 'all for its own' (Ibid: 485). The novel illuminates this “exorcism” and tragically it involves the Ayres children-Caroline and Roderick — both of whom are queer subjects, and both of who are, by the end of the novel, literally removed in one way or another from Hundreds Hall.

Importantly, Butler has made the case for a process through which heterosexual subjects are made intelligible within the heterosexual matrix. She argues that because the materiality of the body is bound to the performativity of gender and she perceives that a normative subject's gender and sexual identity is "formed" (or more properly, performatively performed) through an identification with the 'phantasm of "sex"' followed by a repudiation process that produces the domain of abjection (1993: 3). In other words, Butler suggests that the performativity of heteronormativity (and in this case, heteropatriarchy) requires all "normative" subjects to adhere to the phantasms of sex and gender in order for them to be realized within the heterosexual matrix but then, as part of this "procedure”, repudiate that which is "non-normative”. Without the repudiation process, Butler contends that a heteronormative subject cannot fully 'emerge' (Ibid). Indeed, on this point, Butler is clear 
that 'any refusal or repudiation [of the heterosexual phantasm] creates a valence of “abjection” that itself becomes ‘a threatening spectre’ (Ibid). Put another way, to exist within the heterosexual matrix, a heterosexual subject must recognize that which is abject; it is an integral part of their formation as a "compliant", normative subject, and without it they remain a phantasm in the heterosexual matrix. Of course, within a normative frame, that which is abject is usually that which is deemed queer, for as Butler suggests, it is the fear and rejection of queer subjects that reinforces heteronomativity and regulates it. In relation the novel, then, Faraday not only needs to resolve his crisis of masculinity (if he wishes to be the master of Hundreds Hall) by restoring his place within the heterosexual matrix, but he must complete the repudiation process of which Butler speaks. As I will now go on to show, Faraday narrative reflects Butler process and Faraday identifies in the Ayres children a queerness that to be eliminated.

\section{The Repudiation of Queer Masculinity}

Faraday’s professional status situates him as “equal” to Dr Graham and therefore removes Graham as either a threat or viable subject against whom Faraday's heterosexual repudiation process can be completed. Roderick, however, presents the perfect subject through which Faraday can identify the abject in Butler's heterosexual matrix.

Roderick, as mentioned, challenges gender norms because he represents queer masculinity. Cast in opposition to his father and described as 'not his father's son', Roderick is seen (by Faraday) as lacking through a number of social markers, not least in his inadequate ability to manage the Hall's finances through the period of austerity that have left it in a state of decay (Waters 2009a: 33). Importantly, Robert Heasley defines queer masculinity as a form of male gender that is 'outside hetero-normative constructions of masculinity that disrupt, or have the potential to disrupt, traditional images of the hegemonic 
heterosexual masculine’ (2005: 310). But, while Roderick maybe a queer masculine figure, by virtue of his class and social positioning he is, nonetheless, the "man of the house", the Squire of Hundreds Hall, and it is this socio-cultural status that Faraday seeks for himself. Indeed, Faraday is vocal about the 'envy’ with which he perceives Roderick’s position (Waters 2009a: 153). Moreover, Faraday belittles Roderick almost from the outset, casting him as a "lesser” male by repeatedly referring to him as a 'boy' so as to emphasize his inferiority (Ibid: 230). Roderick is ‘boyish’ and slender, he dresses ‘boyishly', and he is, as Faraday comments, 'the sort of boy to be interested in motors', a comment that infantilizes Roderick as a child with a toy (Ibid: 6, 32). Such social diminishment is echoed by Anne, Dr Graham’s wife, who endorses Faraday’s view, noting that although Roderick is a 'nice’ boy, he is pitied locally because he seems out of his 'depth' (Ibid: 33). As Anne indicates, Roderick had had to grow up ‘quickly’ like all the ‘boys of his age did’ (Ibid: 33). Anne’s words are significant because, while they also infantilize Roderick, they draw attention to the specificity of post-war moment and situate Roderick as a gallant representative of the generation of men who fought for their country as a hero but one whose youth (boyhood) had been stolen. Her words invite empathy with and sympathy for Roderick, but for Faraday they present another measure against which he compares himself, noting the 'cowardice and disappointment' in his own 'undistinguished' war years (Ibid: 39).

Further, because Roderick has suffered long-term injuries from the war, Faraday, as a medic, is able to reconfigure him from war "hero" to war "victim” or casualty. Roderick, a former RAF pilot, had crashed in his aircraft in the war, an incident in which his navigator died. The crash left Roderick with a permanently injured leg, disfiguring burns and, as Faraday also notes, 'a touch of nervous trouble’ (Ibid: 33). This reference is, of course, code for "shell-shock" or traumatic neurosis, disorders that are today termed as post-traumatic stress disorder (PTSD). Faraday draws attention to Roderick's injuries from the outset on his 
first visit to the Hall during which Roderick’s injuries literally precede him. Faraday hears the ‘scrape’ of an irregular footstep before Roderick opens the front door (Ibid: 6). Moreover, without medical evidence, Faraday takes the opportunity to cast his clinical gaze on the Squire, assuming that he is suffering emotionally, noting, in particular, that as he leaves the property he saw Roderick making his 'painful-looking way' to the front door where the house seemed to ‘swallow him up’ as he limps inside (Ibid: 33). Roderick is here portrayed, by Faraday at least, as physically weak and faltering beneath the expectations of his role as heir and squire; the implication that the house "swallowed" Roderick implies that the responsibility is, in Faraday's view, too much for him. As such, Faraday not only perceives Roderick as a queer masculine figure but one failing to meet the expectations associated with the role of heteropatriarchal squire.

While Roderick’s bodily injuries position him as physically subservient to Faraday, it is, however, his emotional injuries that alter the power dynamics between the men as Faraday quickly reconstitutes Roderick as a patient. As noted, Roderick’s nervous disposition is code for shellshock, a disorder that historically has been described as male hysteria. ${ }^{8}$ Although discourse on male hysteria emerged in the nineteenth century and was, like female hysteria, used to encompass a range of so-called nervous disorders, it was following the First World War, with its thousands of traumatized soldiers, that "war hysterics” became a disease to be taken seriously. ${ }^{9}$ However, as Ben Shephard observes, while lessons about shell-shock from the Great War were being learned, sadly they were not always positive. As a consequence of the First World War, treating the large numbers of men who suffered psychiatric conditions was costly for the government, and so plans to avert a similar situation in the case of another war were rapidly put in place in the late 1930s. Importantly, such action relied on psychiatric reports that endorsed the view that nervous illness as a result of war was suffered only by those with a 'constitutional predisposition, either inborn or acquired early in life' to mental 
health disorder (Shepherd 2002: 166). Such pathological and essentialist views of nervous disorders were coupled with criticism from within the medical profession that constituted psychiatry as a ‘queer interest for queer people’ (Ibid: 163). Moreover, the experience of patients themselves was often perceived as 'new and grand' health practices for 'moneyed and lonely women who had had "nervous breakdowns"' (Ibid: 163, 164). Taken together, as Shephard suggests, clinical, governmental and social discourse about men's health often used gendered language with negative connotations, endorsing the notion that psychiatric disorders ostensibly caused by the war in fact reflected an essential "weakness” or lack on the part of the patient himself.

In the novel, Faraday’s approach to Roderick complexly reflects aspects of this troubling rhetoric but couples it with the authoritative power of Faraday’s clinical gaze. Interestingly, in The Birth of the Clinic (1963), in which Foucault traces the birth of the medical profession, he suggests that the clinical gaze, the eye of a doctor, is 'the first face of truth: the eye becomes the depository and source of clarity; it has the power to bring a truth to light' (2003: xiv). Foucault argues that such is the power of the professional physician that historically medical 'truths' have been diagnosed largely through observation (Ibid: 110). Moreover, the privilege that the clinic (that is, the institution of medicine) grants to the 'purity of the [medical] gaze' is 'bound up with a certain silence' (Ibid: 131-132). In other words, seeing and observing equates to a clinical knowing that does not need to be stated or declared; a doctor has unmeasured power by virtue of his or her profession.

Taking into account Shephard's assertion of the pathologizing of war neurosis as a reflection of the weak male subject, Waters shows how Faraday is able to reinforce Roderick as a queer masculine subject and thus abjectify and repudiate him. In the novel, Waters illuminates the subtlety of this process from the outset. Faraday, for instance, observes and “diagnoses” Roderick’s emotional instability, wondering whether is overworking himself and 
eating properly, and speculating just how much his leg injury is a 'nuisance’ to him, observations he attributes to ‘the doctor in me’ (Waters 2009a: 48). Faraday perceives Roderick’s injuries to represent a deeper emotional problem, believing Roderick to be 'punishing' himself through guilt because of the decline of the family estate and/or his wartime past (Ibid: 178). He here exemplifies Foucault’s argument, showing how the medical gaze diagnoses “conditions” before full disclosure or knowledge of medical history is often presented. Later, of course, Roderick does suffer mental health concerns manifest as a psychotic episode in which he envisages a mirror travelling across his room towards him. He repeatedly "trips” and hurts himself when sleep walking in the night, and of course, he nearly dies as a result of a house fire at the hall that begins in his own bedroom. ${ }^{10}$

While these incidents are portrayed so as to invite pity towards Roderick, Faraday seizes the opportunity to reinforce his own superiority and, in turn, Roderick's inferiority. He enforces the fact that Roderick is ill and thus an "abnormal”, queer masculine other against which Faraday’s gender, stature and masculine authority are affirmed. Reflecting Foucault's point on the power invested in the medical profession, Faraday uses his position as a doctor to undermine Roderick's authority, noting his case to be a 'desperate one', words that serve to reinforce both Faraday’s medical expertise and his narrative “clout” (Ibid: 166).

However, crucially, at the heart of the masculine dynamics between Faraday and Roderick is a queer subplot that centres on the treatment of Roderick's physical injuries in which his leg becomes a symbolic substitute for the penis. Interestingly, Foucault asserts that 'the doctor/patient relationship' is often a 'feebly eroticised encounter', a poor substitute for an actual erotic encounter (2003: xvi). Significantly, Eve Kosofsky Sedgwick offers the term 'homosocial' to define 'social bonds between persons of the same sex' (1985: 2). She states that while homosociality can be applied to activities such as "male bonding” which may be characterized by intense 'homophobia, fear and hatred of homosexuality', drawing 'the 
"homosocial” back into the orbit of "desire”", considering the potentially eroticism between men is to hypothesize 'the potential unbrokeness of a continuum between homosocial and homosexual' (Ibid). The important word here is 'potential' because, as Sedgwick states, the visibility of the continuum 'in our society [is] radically disrupted' (Ibid). Put another way, any eroticism between men must is destroyed.

In The Little Stranger Waters provides a detailed account of Faraday's treatment of Roderick’s leg injury that highlights the eroticism of homosociality and the doctor/patient relationship. Roderick’s treatment takes place in the privacy of his bedroom, he partially unclothes himself, and Faraday describes how he ‘squatted’ before Roderick, gently taking hold of the 'injured leg' and drawing it straight (Waters 2009a: 55). Faraday's description of the leg is readily suggestive of male genitalia. It is 'slender' in his hands, 'thick with springing dark hair', 'polished' with 'pink dents and ridges', and is 'pale and bulbous as some queer root, and terribly stiff' (Ibid: 55). Waters’s carefully selected words here knowingly evoke the male phallus, making Faraday’s scrutiny of it homoerotic. Importantly, Bourdieu contends that 'the phallus is always metaphorically present' but rarely named in images of 'fecundating potency' (2001: 12-13). Significantly, the description of the treatment itself soon is synonymous with manual genital stimulation. Faraday, Waters writes, 'gently took hold of the leg again and set it into its natural position' and spends time 'warming and working' the muscle in his hands as Roderick 'leaned forward' to watch him 'do it' (2009a: 56). The scene concludes with the men sharing a cigarette, a suitably post-coital moment.

Sedgwick comments that, 'from the vantage point of our own society [...] it has [...] been impossible to imagine a form of patriarchy that was not homophobic' (1985: 15). Extending this, Donaldson notes that 'heterosexuality and homophobia are the bedrock of hegemonic masculinity’ (1993: 645). Likewise, Connell has argued that although the manifestations and effects of compulsory heterosexuality differ between the sexes, it is also 
often imposed on male subjects by other men. Heteropatriarchy privileges and maintains the dominant social and material status of men at the expense of women as well as sexual others, including queer men (Yep 2003: 20). Indeed, as Monique Wittig valuably argues in The Straight Mind (1992), and Gust Yep points out in his discussion of heteronormativity, because the institution of heterosexuality constitutes masculine subjects as "real” men, homophobia and the fear of being perceived as gay become the central organizing principle around which manhood is culturally policed.

While I do not suggest that Faraday and Roderick are engaged explicitly in homosexual activity, or indeed that either of them are latent homosexuals, I do suggest that Waters shows how the intimacy produced by homosociality and the potential "threat" it poses to a sense of the heterosexual male subject precipitates the same oppression and eradication as overt desire between men. On this point, numerous scholars in the the field of masculinity studies have argued for the necessity of the hetero/homo binary in the formation of the hegemonic male subject. Yep, for instance, contends that 'heteronormativity impels heterosexual men into a lifelong labour of “proving” their manhood and concealing, if not banishing, a range of sexual possibilities, gender performances, and pleasures’ (2003: 20), while Michael Kimmel argues that what the masculinization of sex requires a repudiation of homosexuality in order for the male subject to designate themselves as a “"real” man' (2005: 11). Accordingly, if, in the novel, homosociality subordinates Roderick, then his removal from the Hall (his 'banishing', to borrow Yep’s word) illustrates the primacy of the heterosexual male and the eradication of the queer Other (Ibid). Dispatching Roderick to a care home re-establishing the boundaries of "normal” and “abnormal” masculinity, abject him as a queer masculine subject, and enable Faraday's to complete the repudiation process of which Butler speaks, becoming a legitimized male subject within the heterosexual matrix. 
It is unsurprising, then, that the decision to remove Roderick from the house is taken by Faraday; his power as a medical doctor reinforces his authority and mimics the kind of decision making usually undertaken by the Squire himself. His removal occurs the very day after the family host Faraday to dinner. At the evening prior to Roderick’s departure, Faraday menacingly comments on the family’s position in the room. Mrs Ayres, he notes, took her place at the table's foot while Roderick sits in the 'master's chair', following which Faraday notes Roderick snarls his way through dinner, topping up his glass up repeatedly with wine, and offending Faraday with a comment about him being 'from pirate stock' (Waters 2009a: 187, 190). The reference to class snobbery is significant because it becomes the means by which Faraday displaces his abjection of Roderick (since to admit any homosocial bond would be far too taboo for the heteropatriarchal subject). Accordingly, he follows suit, noting that he 'wouldn't give him the satisfaction of showing any other discomfort' but kept his eyes on Roderick as he ate, 'wanting to stare him out, one man to another' (Ibid: 190). His comment, 'one man to another', not only reinforces the gendered nature of the dynamic between the men but its unspoken competitive edge (for Faraday at least). Moreover, Faraday's strategy proves a success: 'the tactic worked', he comments, 'for he met my gaze with a flutter of his lashes, and just for a moment he looked ashamed and somehow desperate’ (Ibid: 190-191). Faraday’s use of the term 'flutter' here works to feminize Roderick and bolster Faraday's masculine authority. Significantly, it is later that night that a fire takes hold in Roderick’s room, and the day after that Faraday has him committed to a specialist nursing home for emotional disorders. While this protracted discussion of masculinity suggests competition for the role of "alpha male" at Hundreds Hall, the point of it is to both establish how Waters exposes the subtle ways in how heteropatriarchal masculinity is produced and how it functions between men. In doing so, she sets up the foundation for a further study of masculine domination over women. This point is important because 
heteropatriarchy is, as feminists have long argued, a form of social ordering in which men are perceived as dominant and women are positioned as subservient. Together, they embody what Rich names ‘compulsory heterosexuality’ (1986: 23). The “goal” of the social Darwinian dynamics played out at Hundreds Hall then is twofold: acquisitions of the Ayres women and through them, acquisition of the Hall, which, with its class and stature provide will Faraday with gender security and social elevation.

\section{Queer Femininity and Masculine Domination}

If Faraday’s engagement with Roderick plays out a masculine "survival of the fittest” competition (so to speak) so as to establish one male (Faraday) as the "real" "man of the house”, Faraday’s relations with the women of Hundreds Hall serve to bolster his masculine supremacy and expose the perniciousness of heteropatriarchal domination through the oppressing of women. Importantly, Butler suggests that because hegemonic heterosexuality is not independently constituted and stable it has to continuously re-affirm itself through repeated performance:

Hegemonic heterosexuality is itself a constant and repeated effort to imitate its own idealisations. That it must repeat this imitation, that it sets up pathologising practices and normalising sciences in order to produce and consecrate its own claim on originality and propriety, suggests that heterosexual performance is beset by an anxiety that it can never fully overcome, that its efforts to become its own idealisations can never be finally or fully achieved, and that it is consistently haunted by that domain of sexual possibility that must be excluded for heterosexualised gender to produce itself (1990: 125).

As Butler indicates, because heterosexuality is both an institution and an identity, it is bound to a continuous and unending cycle of repetition and compulsion. In the novel, Faraday points 
to such a "before" and "after" in his relations with the Ayres family, commenting that with Roderick's removal, it was clear to all that Hundreds had entered a 'distinct new phase' (Waters 2009a: 235). What he means here, of course, is that he begins to ingratiate himself in the (vacant) role of patriarch. But according to Butler's theory, Faraday’s "split” between a pre-and-post-Roderick context is a misnomer; instead, Faraday simply trades one cycle of ‘compulsion' for another, and with it, the “victim” of heteropatriarchal domination; man for woman (Ibid).

Reflecting how Faraday measures himself against alternative forms of masculinity, so too he measures the Ayres women against their “allegiance” to heteronormative ideals of femininity. Feminists have long argued that one of the ways in which heteronormativity manifest is through what Rubin describes as 'obligatory heterosexuality, Jackson has condemned as ‘compulsive heterosexuality', and, as noted earlier, what Rich terms ‘compulsory heterosexuality’ (Rubin 1975: 179; Jackson 1999: 142; Rich 1986: 227). Under any of these names its nature and function is the same: 'compulsory heterosexuality' creates the conditions by which women are denied being 'anything else' but heterosexuality and channels women into limited representations of femininity, marriage and motherhood (Kitzinger and Wilkinson 1993: 31). As noted earlier, feminist scholars argue that heterosexuality is a prime facet through which male power and dominance is managed and maintained, transforming it from a mode of sexuality into a patriarchal institution that functions to subordinate, degrade and oppress women (Yep 2003: 19). ${ }^{11}$ And, because heteropatriarchy is "normalised”, its violence is overlooked and normalised, a point I shall return to.

While Faraday views the Ayres women rather differently, they are nonetheless considered through the same heteronormative lens. He measures them against what he believes the "correct” embodiment of "woman” should be according to heteropatriarchal 
parameters. This sets up an oppressive yet competitive dynamic between Mrs Ayres and her daughter in which Faraday perceives that Mrs Ayres excels at being “woman” (in the heteronormative sense of the term) and Caroline is somewhat faltering. Mrs Ayres, for example, is described as an 'old-fashioned lady' clinging to the affectations of the pre-war era in which she enjoyed and relished her role as the renowned Colonel and squire's wife (Waters 2009a: 425). She affirms Faraday's nostalgia for gendered traditions of the past, noting that her to be part of a 'different, more gracious age', words that reinforce a wistfulness for a "golden age” of Victorian and Edwardian heteronormativity (Ibid). Faraday approvingly comments of Mrs Ayres's stature, hands and dress, comparing her to a 'French' widow (Ibid: 83). His use of the word 'French’ points to the perceived view that French fashions epitomize normative modes of feminine gender with style. Aptly, given his continued admiration for Mrs Ayres, it is unsurprising that, as Dr Seeley notes, there is 'quite a little debate locally' as to which of the women 'you've set your sights on-the daughter or the mother' (Ibid: 263).

By contrast to his views of Mrs Ayres, Faraday is less approving of Caroline, of whom he is decisively critical. After noting that Caroline’s handshake was firmer Roderick's, his first comments of her are unflattering at best, and worth quoting at length. He describes Carole as:

noticeably plain [and] over-tall for a woman, with thickish legs and ankles. Her hair was [...] with proper treatment, have been handsome, but [...] it fell drily to her shoulders, as if she had washed it with kitchen soap and then forgotten to comb it. Added to that, she has the worst dress sense of any woman I ever knew. She was wearing boyish flat sandals and a badly fitting pale summer dress, not at all flattering to her wide hips and wide bosom. Her eyes were hazel, highly set; her face was long 
with an angular jaw, her profile flattish. Only her mouth, I thought, was good: surprisingly large, well-shaped and mobile. (Ibid: 9)

Faraday’s choice of descriptors is unbecoming in comparison to those he deploys in relation to Mrs Ayres, choices that subtly exposes his strict expectations of "woman" and “femininity” and affirm Caroline as a queer feminine subject. His observation, for instance, regarding Caroline’s height imply a perception of what the "proper” height of "woman" should be as well as reveal a concealed sense of threat. Likewise, his spiteful comment about her hair affirms his critical nature and points to "standards" of female appearance, a notion reinforced by reference to her specific clothes as ill-fitting and 'not flattering' to her broader bosom and hips_-both of which, interestingly, are features — that reinforce Naomi Wolf's views in The Beauty Myth (1990) that women's gender is interrelated with, and violently controlled by, myths concerning socially constructed expectations of beauty. Such a notion is also reinforced in the scenes surrounding the dog-bite suffered by Gillian, when it is noted that her 'frightful' scarring will be all the worse 'for a girl of her class' (Waters 2009a: 106).

\section{Masculine domination and symbolic violence}

Through the portrayal of Faraday's relationship with Caroline, Waters draws attention the pernicious nature of men's subjugation of women. Despite his earlier observation (albeit negative) of Caroline's hips and breasts, for the main part of the story, Faraday is not romantically or sexually attracted to her, a point reinforced by his continued criticism of her appearance. But this changes following the occasion of the hospital dance when he becomes uncomfortably enamoured of her. Sadly, as John Mullen rather humorously puts it, their “relationship”, which Faraday describes as 'a courtship’ is, in fact, 'physically awkward' (Ibid: 323; Mullen 2010: n. p). Despite admiring Caroline’s appearance on this occasion, Faraday is quickly persuaded by Dr Seeley's mocking comment that although there is 
‘something there’, Caroline doesn’t have the looks to match’ (Waters 2009a: 263). As well as objectifying Caroline in a pejorative fashion, Seeley diminishes her as a figure of femininity, and Faraday takes offence not because his colleague has been rude about Caroline and/or insulted his date; rather, he is embarrassed by the fact that any judgment on her and reflects on him: 'I felt I'd been made an ass of' (Ibid: 263). Faraday laments that he had had given little consideration for how the 'thing would look', and that he was embarrassed 'to have my name romantically linked to that of a notoriously plain girl' (Ibid: 264). His words emphasize his sense of patriarchal superiority, and positions Caroline, his superior in class, as his inferior in gender and sexual terms.

Through her portrayal of the acceleration of Faraday and Caroline's relationship, Waters reflects the queer theoretical view that 'Western political thought has taken the heterosexual couple to represent the principle of social union itself' (Warner 1993: xxii). It is only a short time after the hospital dance that the couple get engaged. In formalizing their relationship, Faraday validates his position within the heterosexual matrix, but taking the next step—-marriage—-means that he will become the heteropatriarchal Squire of Hundreds Hall. However, following their engagement Waters demonstrates explicitly the nature and function of masculine domination, endorsing Bourdieu's view that 'kinship and marriage [...] assigns to women their social status as objects of exchange defined in accordance with male interests to reproduce the symbolic capital of men' (2001: 43). Faraday's expectation of “woman” quickly grow soon after the couple are engaged, extending beyond the corporeal and aesthetic and into women's behaviour, exposing the violence of heteronormativity as a socio-cultural regime. For instance, despite Caroline’s plea not to reveal news of their engagement to Mrs Ayres who is, by this point, rather poorly, Faraday is impatient to share the news in order to 'get things moving' (Waters 2009a: 323). Likewise, Faraday ignores Caroline's insistence on keeping news of their engagement secret following her mother's 
death, happily revealing the news to her friends and agreeing with them that it was 'by far the best thing that could happen to Caroline now'(Ibid: 421).

Waters also exemplifies how masculine domination takes place through physical contact. Faraday quickly becomes frustrated by Caroline’s refusal to let him touch her but nonetheless says that 'Now and then I chanced it' (Ibid: 324). Indeed, Waters reinforces how masculine domination often manifests through physical/sexual imposition. Although he knowing that Caroline was 'never' at ease with him and is openly resistant to his touch, Faraday sexually pursues her:

She'd stand against me with her head averted, her arms hanging loosely at her sides [.] And if ever, frustrated, I pressed further, the result was disaster. Her soft limbs would harden, her hand come up across her face. 'I’m sorry', she'd say [...] I just need a little more time (Ibid: 324)

Faraday's account subtly reveals the coercive nature of his touch; the passivity of her soft limbs 'hanging loosely’ is juxtaposed with Faraday’s active pressing (Ibid). This knowing action shows how masculine domination often takes place through persistent pressure and gradual force. Moreover, his assessment that his efforts results in disappointment suggest his own frustration and displeasure at the boundaries and limitations Caroline is placing on their intimate relations.

Likewise, Waters also exposes Faraday's masculine domination in the way that he persistently seeks to orient Caroline toward his own conception of "woman" which, as noted, is more akin to that represented by Mrs Ayres. He becomes annoyed, for instance, that despite the change in their relationship, Caroline continues to wear her 'shapeless old sweaters and skirts, her rough wool hats and stout shoes' (Ibid: 324). In other words, Faraday wants a "womanly woman" to compliment his newfound status as a soon to be patriarch (or “manly man”). Here the novel demonstrates Bourdieu’s observation that the social 
construction of gender according to heteronormative modes of being produces and perpetuates the pervasive and insidious power of masculine domination that defines heteropatriarchy as 'the established [gender] order, with its relations of domination, its rights and prerogatives, privileges and injustices' (2001: 1).

In addition, through the scenes surrounding the couple's engagement Waters exposes how masculine domination is a pernicious form of symbolic violence that imposes order and restraint on "non-normative” (or even, non-compliant) queer subjects through indirect cultural mechanisms (as opposed to coercive or forced control). ${ }^{12}$ Symbolic violence describes the imposition of systems of meaning upon subjects 'in such a way that they are experienced as legitimate’ and applies to ‘any social formation, understood as a system of power relations and sense relations between groups or classes' (Jenkins 1992: 104). It is a form of violence ‘exercised upon [a subject] with his or her complicity', meaning that the subject (the dominated) accepts the values and behaviours of the dominant group as legitimate (Bourdieu and Wacquant 1992: 167). The effect of legitimacy obscures the power relations between subjects or groups, making them unrecognizable to, and misrecognized by, the dominant. Bourdieu comments that:

Masculine domination [and] the way in which it is imposed and suffered [is] the prime example of [...] symbolic violence, a gentle violence, imperceptible and invisible even to its victims exerted through the most part through the purely symbolic channels of communication and cognitions (more precisely, misrecognition), recognition, or even feeling (Ibid: 2).

Indeed, because symbolic violence is distinct from "actual” physical violence, it frequently occurs through contextual means relevant to the behaviours of that which is being imposed, the effect being that the imposed behaviours are presented as the "correct way" of doing things; it creates a perception of "good” pedagogic intervention. Moreover, in a gendered 
context, Bourdieu argues that masculine domination as a form of symbolic violence often manifests in the form of 'suggestions, seductions [,] reproaches, orders or call to order' that reinforce the 'hypnotic power’ of the male (Ibid: 42).

In the novel, Waters exemplifies Bourdieu’s concerns, highlighting the hidden and devious means through which Faraday’s symbolic violence manifest. For instance, Faraday notes that Caroline seems 'unable to plan for the wedding' so he assumes control of the occasion, revelling in the detail of the event and, on more than one occasion, pressuring her to set a date (Waters 2009a: 438). Moreover, Faraday combining the power of his clinical gaze with his domineering behaviour, Faraday begins to plan ‘our honeymoon’ because he 'imagined all the good it would do her to be taken out of the country' (Ibid: 438). However, as the wedding grows nearer, he becomes increasingly frustrated by Caroline's indifference toward the occasion but continues to try and encourage her to plan anyway, bluntly reminding her that she had 'better choose [... ] a bridesmaid' (Ibid: 439). When she responds apathetically (in his view) with the words, 'Must I', Faraday assumes control, deciding that he will speak to one of her friends and arranges the matter of her bridesmaid on her behalf. Further, when Caroline appeals to her fiancé to slow down the wedding planning, he dismisses her request, asking 'what have we to wait for?' and ignoring the fact that Caroline simply looked frustrated, but ‘didn’t answer’ (Ibid: 440-441). Irrespective, Faraday purchase Caroline’s wedding dress for her, a decision he makes because Caroline 'had given no thought' to her wedding clothes and Faraday fears that she will not look feminine enough on their wedding day, noting that Caroline says she would 'put something together from the things she had upstairs’, a thought which made in 'inwardly’ shudder (Ibid: 442). Here his words reveal indignation towards Caroline’s non-compliance with heterosexual and feminine “normalcy”, reflecting Wittig’s observation that through the 'heterosexual contract', women 
must be constituted as "real" women by being seen to conform and comply with expectations of “woman” (1992: 44). Here, in this case, of being a radiant bride.

Moreover, the novel represents the long-standing feminist concern that heterosexual norms are managed through the institution of marriage. Faraday manipulates his power as a medic with his newfound role as Caroline’s fiancé to assume control over her future. For example, when Caroline is upset about her mother's health and Faraday suggests committing her (like Roderick) to a clinic, he reassures her with the words 'Once we are married-_', to which Caroline angrily reminds him 'We aren’t married yet. God!’ (Waters 2009a: 397). By reinforcing marriage as a mechanism for masculine domination, Waters conveys Rich’s contention that marriage is the definitive site of 'compulsory heterosexuality' (1986: 23).

Bourdieu suggests that the only way to break the cycle of masculine domination as symbolic violence is through 'a radical transformation of the social conditions’ (2001: 42). Significantly it is following this peak of wedding-related activity that Caroline ends the engagement, telling Faraday that she had been 'confusing liking [you] with...something else' and advising him that she has decided to emigrate to Canada (Waters 2009a: 446). In an uncomfortable exchange with Faraday, Caroline vocalizes her rejection of heteronormative gender conventions and compulsory heterosexuality_ 'I can't be a doctor’s wife. I can’t be anybody’s wife’ — and asserts her queer femininity (Ibid: 447). The effect, however, escalates Faraday’s masculine domination, shifting it from one of symbolic violence to actual violence as he violently throws the wedding ring he had purchased at Caroline, meaning it to 'hit her' (Ibid 450).

As a study in heteropatriarchal masculinity, Waters goes on to describe the effects of Faraday’s loss. In the immediacy of the exchange, Faraday is shocked, angry and 'humiliated' by Caroline (Ibid: 453). As he puts it: 'The simple loss of Caroline was hard enough to bear, but the loss of her was so much more. Everything I'd planned and hoped for 
[was] melting away from me! [...] I couldn’t bear it' (Ibid). Faraday’s words here recall the anti-feminist and misogynistic words offered by Clare for the recent “crisis” in masculinity, evoking Clare’s concern for the 'growing assertiveness of women' as overthrowing 'male power’ (2000: 3-4). Faraday’s “plans” are similarly dashed by Caroline’s agency. He had assumed that marriage would change his life and morph him into a 'new man' (Waters 2009a: 468).

Accordingly, with the cancellation of the engagement, the wedding plans, and his intended future, Faraday is denied the possibility to become who he aspires to be, the legitimate heteropatriarchal squire of Hundreds Hall. Accordingly, his position in the heterosexual matrix is once again unstable, called into question by Caroline's rejection and dismissal of him. As such, his process of "becoming”, as theorized by Butler, is incomplete, a point reinforced by his final and rather ambiguous statement that three years since the events the community still saw him as 'a sort of “coming man”'—-someone with promise and potential', although as his words implicitly reveal, never quite achieving that (Ibid: 494). As he puts it, his position becomes ‘queer and wrong’ (Ibid: 473).

Although Waters portrays Caroline’s death with a degree of ambiguity that leaves open to interpretation who or what killed her (a point reinforced by the open verdict recorded at the inquest into her death), there are sufficient clues pointing towards Faraday as her murderer. Not only does Faraday have a key to Hundreds Hall, but he rather menacingly visualizes her death at the inquest, and feels 'wretched', confused, and has a 'curious shame' about the incident, before realizing what happened but noting the moment had 'passed' and it was too late to speak (Ibid: 477). Moreover, earlier in the novel, at the height of his frustrated desire for Caroline, he reveals that at night his mind would 'go softly across the darkened miles between us, to slip like a poacher through the Hundreds gate [...] and then go creeping, creeping towards her' (Ibid: 325). Faraday’s words here are important as they suggest 
forcible possession and a (prospective) rape fantasy. Moreover, his words foreshadow the way in which he comes to murder Caroline later. He is the mysterious person that she calls out to on the landing before "falling” to her death, and Betty's account of the night- that she heard Caroline speak to a person she knew and was 'afraid of' before running—suggest that Caroline was indeed assaulted by Faraday (Ibid: 483).

As a queer female subject, Caroline pays the ultimate price for non-conformity to the conventions of gender and sexuality; she is murdered, a notion that reinforces the ‘compulsory heterosexuality’ as a form of social violence against women. Of course, Roderick, too, pays the same price, but rather than being killed, he is removed from sight. In this way, Faraday's narrative symbolically implies that queer subjects literally have no place in society and they must be removed or "exorcised" for failing to adhere to heterosexual normalcy.

In a final critique of masculine domination, Faraday’s silence in conveying the truth of where he had been on the night Caroline had died is uncomfortable. He allows his colleague to believe that he had been in nearby Leamington Spa and not nearby. Further, he posits the suggestion of Caroline’s suicide, cunningly displacing the idea onto Dr Graham. Moreover, that in court he is able to give his own account of his relationship with Caroline and leads the court to believe that she had been feeling low before her death, shows how even in death Caroline is controlled and manipulated by the heteropatriarchal male who gets to mediate her life.

To conclude, although The Little Stranger articulates the invisible mechanisms of masculine domination in operation, it does not assert what is right or wrong about heterosexuality as an institution. Rather, Waters demonstrates what is at stake when heteropatriarchal males are enabled to attain power over other persons, “non-normative” or otherwise. As a study in the "production" of the heteropatriarchal male, the novel critiques 
the institution of heterosexuality and like queer theory, serves to interrogate, examine, unpack and debunk regimes of the "normal”. In doing so, Waters illuminates the queer/heterosexual binary, challenges (the primacy of) normative assumptions about gender and sex/uality and the regulatory function of normalizing techniques. Although the novel's queer subjects die or are removed from society, the text offers a commentary on the necessity for further scrutiny of, and resistance towards, the politics of heteropatriarchy. As such, The Little Stranger is an important feminist and queer corrective, in fictional terms at least, to the ways in which heteropatriarchal men position themselves.

\section{Notes}

${ }^{1}$ In existing criticism of the novel, Lucie Armitt (2011) has explored the representation of the Gothic in the novel and the made the case for Caroline as a latent lesbian subject (2007), Ann Heilmann (2012) has placed the novel in dialogue with Victorian literature and culture, Joanne Bishton (2012) has considered the role of queer narration in the novel, and both Katherina Boehm (2011) and Emma Parker (2013) has discussed the book in relation to the country house novel.

${ }^{2}$ For an excellent overview of existing analysis of heterosexuality as an institution and queer and feminist readings of its portrayal in contemporary fiction, see Rachel Carroll's Rereading Heterosexuality: Feminism, Queer Theory and Contemporary Fiction (2012).

${ }^{3}$ Boehm (2011) suggests that nostalgia is evidenced in the novel's representation of the materiality of history. Likewise, both Armitt (2011) and Parker (2013) have considered the ways in the nostalgia of class politics are prevalent in the novel, important observations that I shall return to and build upon.

${ }^{4}$ See Heilmann’s excellent 2012 essay, 'Specters of the Victorian in the Neo-Forties Novel: Sarah Waters's The Little Stranger and its Intertexts' in Contemporary Women's Writing. 
${ }^{5}$ Although the bachelor is an important figure in the analysis of masculinity in Victorian literature, in the mid twentieth-century, the concept holds less authority because of the mass loss of men following the two world wars.

${ }^{6}$ See Mary Louise Adams, The Trouble with Normal (1997), Barbara Ehrenreich, Fear of Falling: The Inner Life of the Middle-Class (1989) and Alice Ferrebbe, Masculinity in the Male-Authored Novel 1950-2000: Keeping it Up (2005).

${ }^{7}$ As in Affinity Waters uses spectrality as a recurrent motif throughout the text. Waters's predilection for Gothic fiction is captured in her list of 'Top Ten Ghost Stories’ that was published on her website in March 2009 to coincide with the publication of the novel (see <http://www.sarahwaters.com/2009/03/31/sarah-waters'-top-ten-ghost-stories/>). But whereas in Affinity it is “Peter Quick” (aka Ruth) who "haunts” London’s middle-class women as a means of engaging in same-sex behaviour with, Selina, the ghost at the centre of The Little Stranger remains more elusive, generating considerable debate as to who or even what the ghost is that is haunting the Hall.

${ }^{8}$ For a comphensive overview of the history of male hysteria and its connection to historical conceptions of degeneration and decline, psychoanalysis and criminality, sexual decadence and homosexuality, see Mark S Mirale’s book Hysterical Men: The Hidden History of Male Nervous Illness (2008) (2008).

${ }^{9}$ For more on this see Ursula Link-Heer and Jamie Owen Daniel’s article “"Male Hysteria”: A Discourse Analysis’ (1990).

${ }^{10}$ Waters also uses intertextual allusion to reinforce Roderick’s hysteria. As Heilmann notes, his room is decorated in yellow paper, a reference to the wallpaper of the attic room in which the protagonist of Charlotte Perkins Gilman's The Yellow Wallpaper (1892)—a story about female hysteria—is confined by her husband (2012). 
${ }^{11}$ For more on this point, see Delphy and Leonard, Familiar Exploitation: A New Analysis of Marriage in Contemporary Western Socieities (1992); Jackson, Heterosexuality in Question (1999); Kitzinger and Wilkinson (eds.), Heterosexuality: A Feminism and Psychology Reader (1993); and Sylvia Walby’s Gender Transformations (1997).

${ }^{12}$ A number of feminist scholars have used Bourdieu's analysis to chart the sociological operation of gender inequality. See, for instance, Lisa Adkins and Beverley Skeggs, Feminism After Bourdieu (2004); Judith Butler’s Excitable Speech (1997) and ‘Performativity’s Social Power’ (1999); Amy Lovell’s ‘Resisting with Authority’ (2003); Lois McNay’s ‘Gender, Habitus and Field’ (1999) and ‘Gender and Agency’ (2000); Toril Moi’s What is a Woman? (1991); and Beverley Skeggs’s Formations of Class and Gender (1997). 